\title{
Enemigos del comercio: Un análisis de las ideas económicas en la novela decadente
}

\author{
Francisco CABRILlo \\ Universidad Complutense de Madrid, Facultad de Derecho, Ciudad Universitaria, s/n., 28040 Madrid, \\ España.E-mail: fcab22@terra.com
}

\begin{abstract}
RESUMEN
En las dos décadas finales del siglo XIX surgió la novela decadente como una oposición al realismo y al naturalismo, las corrientes dominantes hasta aquel momento. Los decadentes eran críticos de la industrialización, del mundo financiero y de la economía de mercado en general. Los novelistas cuya obra se analiza en este artículo -Huysmans, D'Annunzio y Wilde- añoraban un pasado imaginario en el que la nobleza y el arte eran las fuerzas que guiaban la sociedad, idea que se puede encontrar expuesta de forma más sistemática en la obra de autores como Carlyle o Ruskin. El desprecio por el comercio y las actividades económicas que sentían los escritores decadentes desempeña un papel importante en la mayoría de sus novelas.
\end{abstract}

Palabras clave: Decadentismo, crítica a la economía de mercado, pensamiento conservador.

\section{Enemies of Commerce: Economic Ideas in the Decadent Novel}

\begin{abstract}
In the final two decades of nineteenth century decadent novel was born as an alternative to realist and naturalist novels, the mainstream in those years. Decadent writers criticized industrialization, finances and the market economy at large. The novelists whose work is discussed in this paper -Husysmans, D'Annunzio and Wilde- longed for an imaginary past in which nobility and art were the main forces in society, an idea that was developed more systematically in the works of Carlyle or Ruskin. Contempt for trade and economic activities is an important element in most decadent novels.
\end{abstract}

Keywords: Decadentism, Critique of the Market Economy, Conservative Thought.

Clasificación JEL: B19, Z1

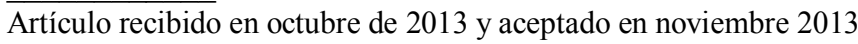

Artículo disponible en versión electrónica en la página www.revista-eea.net, ref. ə-32115 


\section{INTRODUCCIÓN}

En el mes de mayo del año 1884 se publicó en París $A$ contrapelo $-\grave{A}$ rebours, en su título original- ${ }^{1}$ un libro que fue el origen de una nueva forma de entender la novela, cuyos seguidores formaron un grupo que sería pronto tachado de "decadente". Como en cualquier movimiento artístico o literario no resulta fácil definir con precisión sus rasgos. No todos los autores que pueden ser considerados como decadentes son iguales, ciertamente. Pero no cabe duda de que tienen muchos puntos en común. Entre ellos, el tema que constituye el núcleo de este artículo: el rechazo de la civilización burguesa del siglo XIX; y, como uno de los rasgos más característicos de ésta, la economía de mercado. Para ellos el arte, el heroísmo y la nobleza deberían ser los fundamentos de la sociedad. Despreciaban, en cambio el comercio, el ahorro y las finanzas, así como a las personas que se interesaban en estas actividades. De alguna forma anhelaban volver a un pasado imaginario en el que, la estética ocupaba un lugar preferente en el mundo de los escogidos.

Aunque al decadentismo en el arte no se limitó a la novela, y desempeñó un papel muy importante en la poesía, la música o las artes plásticas, este artículo se centra en la prosa, que es el género que permite analizar mejor las ideas económicas y sociales del movimiento. El ensayo se centra en tres novelas de tres autores diferentes, escritas en lenguas y países distintos. Además de la ya mencionada obra de Huysmans, se estudiará la primera de las grandes novelas de D’Annunzio, El placer; y la que es, sin duda, la obra más famosa de Oscar Wilde, El Retrato de Dorian Gray. ${ }^{2}$

Los tres libros son estrictamente coetáneos, y fueron publicados en un período muy breve de tiempo, el transcurrido entre 1884 y 1891 . La relación entre las novelas es clara, y sus protagonistas tienen mucho en común. Todos pertenecen a la clase social más alta y viven en ambientes dominados por el arte y el lujo aristocrático. Sin embargo, la visión del mundo que se obtiene de la lectura de estas obras no es optimista. Las tres tienen un final bastante deprimente. Y nada define mejor su significado que aquella frase de Barbey D'Aurevillly -hombre muy ligado al movimiento y amigo personal de Huysmans- quien, tras

\footnotetext{
${ }^{1}$ La novela se ha traducido al español de diversas formas: Al revés, Contra natura y A Contrapelo, siendo esta última la que, seguramente, recoge más con mayor fidelidad la idea del autor.

${ }^{2}$ Las ediciones utilizadas en este trabajo son las siguientes:

- Huysmans, J.K. À Rebours. París: Frame Loisirs, 2003

- D’Annunzio, G. Il Piacere. ed. a cargo de Gianni Oliva- Roma: Newton, 1995

- Wilde, O. The Picture of Dorian Gray. En The Works of Oscar Wilde. Edición a cargo de G.F. Maine. London: Collins, 1963.

Las páginas citadas en el texto corresponden a estas ediciones. Dada la naturaleza del artículo, no se han utilizado ediciones críticas y se ha prescindido de posibles variaciones en las diversas ediciones. Las traducciones de los textos son del autor del artículo.
} 
leer $A$ contrapelo, relacionó esta novela con la principal obra poética de Baudelaire y escribió: "Después de Las flores del mal -le dije a Baudelaire- no le queda a usted otra opción que elegir entre una pistola o los pies de la cruz. Baudelaire escogió los pies de la cruz. ¿Hará lo mismo el autor de $A$ contrapelo?”3. $\mathrm{Y}$ es evidente que lo hizo. Sin renunciar a sus principios estéticos, Huysmans abrazó la religión y fue el resto de su vida un católico ferviente, llegando a residir largas temporadas en un convento.

\section{CONSERVADORES CONTRA LA ECONOMÍA DE MERCADO}

Las críticas a la sociedad burguesa y liberal tenían ya una larga tradición a finales del siglo XIX. Por ello los novelistas del decadentismo no crearon de la nada su visión crítica de la sociedad de la época. Esta actitud era, en realidad, heredera de una dilatada historia de resistencia al progreso que había surgido en el romanticismo. La añoranza del mundo agrario o de la economía gremial creció, de hecho, a medida que la industrialización avanzaba y el mundo de las finanzas y las grandes empresas se convertían en los protagonistas de la vida social.

No debería olvidarse que el Manifiesto Comunista abre la sección dedicada a la "Literatura socialista y comunista" con un apartado dedicado al "socialismo reaccionario", cuyo primer representante sería lo que en el texto se denomina "socialismo feudal". No es difícil imaginar lo negativo de la opinión de Marx y Engels sobre aquellos escritos que definían como "mezcla de lamento, eco del pasado.... incapaz de comprender la evolución de la historia moderna" ${ }^{4}$. Los autores del Manifiesto consideraban sus principales representantes a una parte de los legitimistas franceses y al movimiento denominado la "Joven Inglaterra", cuya principal figura fue Disraeli. Y habría que añadir que sus ideas guardaban una estrecha relación con uno de los intelectuales británicos más destacados de la época, Thomas Carlyle.

Carlyle es conocido en el mundo de la economía especialmente por su definición de esta disciplina como la "ciencia fúnebre". Pero es un autor muy importante a la hora de estudiar el pensamiento conservador anticapitalista. Carlyle no sólo fue crítico de la Revolución Francesa. También estaba en contra de la Ilustración y, desde luego de la democracia y del parlamentarismo. "Un hombre vive -escribió- creyendo en algo, no discutiendo y debatiendo sobre muchas cosas". Sus ideas económicas no son fáciles de sistematizar. A pesar de sus principios políticos conservadores fue muy crítico con la aristocracia tradicional, a la que valoraba muy poco. Pero no creía tampoco en la economía de su

\footnotetext{
${ }^{3}$ Baldick (1958), p. 117.

${ }^{4}$ Marx (1965). 1, pp. 183-184.
} 
época, a la que consideraba carente de ética. Muy contrario al utilitarismo y a la economía clásica inglesa, trató con desdén la producción en masa de productos de mala calidad elaborados para un gran número de consumidores y defendió, en cambio, a los artesanos y sus gremios; idea que influyó claramente en Ruskin. $^{5}$

En un estudio sobre las ideas económicas en la literatura, resulta especialmente interesante su visión del "héroe". En 1841 publicó Carlyle un libro con el expresivo título On Heroes, Hero Worship and the Heroic in History en el que a través de una serie de biografías de personajes tan diversos como Dante, Lutero o Napoleón insistía en la importancia del liderazgo de los héroes en la historia. Y su última obra importante fue una biografía de Federico II de Prusia; para escribirla viajó a Alemania, especialmente interesado en visitar los campos de batalla en los que había obtenido sus principales victorias Federico el Grande. No es sorprendente que esta mezcla de ideas en contra de la economía liberal y la democracia y en favor de los héroes y la organización económica del pasado, haya llevado a encontrar en su obra precedentes de las ideas que servirían de base a los fascismos europeos del siglo veinte. ${ }^{6}$

La figura del aristócrata frente al hombre-masa constituye un elemento definitorio del decadentismo, como más adelante veremos con ejemplos concretos. $\mathrm{Y}$ el culto al arte es un principio sin el cual no pueden entenderse estas novelas. Por ello la obra de John Ruskin es también importante para el estudio de la literatura decadente. Nacido en 1819, con poco más de veinte años Ruskin era ya un especialista y crítico reputado en pintura y arquitectura. Pero pronto empezó a ocuparse también de las relaciones entre el arte y la sociedad en la que éste se desenvuelve y se convirtió en un enemigo radical del capitalismo del siglo XIX. Sus escritos son un buen reflejo de esa opinión distante y crítica de la realidad económica que compartían quienes se encontraban inmersos en el mundo de la alta cultura y observaban la vida social desde el punto de vista de la estética, muy alejados de la forma en la que veían el mundo la mayoría de las personas a las que los intelectuales y artistas intentaban educar.

Su obra más interesante para un estudio sobre las ideas sociales y económicas de la época es un pequeño libro en el que presentó, de forma más o menos sistemática, su visión de la economía y el arte. El origen de esta obra se encuentra en unas conferencias pronunciadas en Manchester el año 1857 y publicadas como The Political Economy of Art, título que más tarde se transformaría

\footnotetext{
${ }^{5}$ Para una visión global del pensamiento social de Carlyle y otros autores críticos de la economía de mercado véase el libro clásico -aunque ya antiguo- de H. Rose. Rose (1891).

${ }^{6}$ Es sabido, por ejemplo, que el Dr. Goebbels, que era muy crítico con las clases altas tradicionales alemanas y defendía abiertamente una economía socialista para la nueva Alemania apreciaba mucho su obra.
} 
en A Joy for Ever, expresión tomada del famoso verso con el que Keats abre su poema "Endymion": "A thing of beauty is a joy for ever".

Si consideramos la época en la que el libro fue publicado, resulta realmente sorprendente comprobar lo poco que de economía sabía su autor... y el poco interés que tenía por aprender algo más. En el prólogo de la obra Ruskin confesaba, sin ambages, que el único libro de economía que había leído en su vida era La riqueza de las naciones; y que habían transcurrido ya veinte años desde que lo había hecho. El resultado es una obra que no tiene mucho que ver con la que alguien con algún conocimiento profesional de la materia escribiría; pero que contiene numerosas reflexiones sobre temas económicos; en especial sobre cuestiones relacionadas con el mundo del arte.

Pensaba Ruskin que en el mundo existen dos tipos de hombres, aquellos que tienen "jardines, bibliotecas y obras de arte" y aquellos que no las tienen. Y en estos últimos incluía tanto a los que no disponen de medios para disfrutar de estos bienes como a aquellos que, aun teniéndolos, sólo se ocupan de conseguir dinero y objetos de lujo, a los que no duda en denominar "personas innobles". El mundo ideal para él sería aquel en la que la gente pudiera combinar una vida simple con la sensibilidad artística; en sus propias palabras, "la unión de Esparta con Atenas"7. La economía debería basarse en la honradez y en la ética, tanto por parte de los que venden como por parte de los que compran. Cada artículo debería tener su "propio valor"; los comerciantes nunca deberían poner un precio más alto y los clientes no tratar nunca de obtenerlo por menos. ${ }^{8}$ Por ello afirmaba, por ejemplo, que los cuadros no deberían ser baratos; y ningún libro se debería vender por un precio inferior a una libra, con la excepción de las personas realmente pobres a las que se ofrecerían libros gratuitos en cantidades limitadas. Si los costes de producción fueran más bajos, se podría crear con la diferencia un fondo que permitiría reducir los impuestos. El objetivo de Ruskin era, claramente, dignificar el arte y la cultura; y no parece que fuera consciente de que en realidad defendía un impuesto sobre el consumo de obras literarias, que no tendría precisamente un efecto muy positivo para crear esa sociedad ateniense que él perseguía. ${ }^{9}$ En ella el Estado tendría que desempeñar un papel muy importante en la promoción de las artes, ofreciendo educación en este campo y creando empresas que suministraran papeles, tintas y colores de calidad.

En esta nueva economía, basada en principios éticos, la gente no debería confiar sólo en las demás personas; también tendría que fiarse del Estado, que

\footnotetext{
${ }^{7}$ Ruskin (1907), pp. 172-173.

${ }^{8}$ Ibid., p. 179.

${ }^{9}$ Ibid., pp. 66-67.

${ }^{10}$ Ibid., pp. 31 y $43-44$.
} 
actuaría de forma responsable buscando el bienestar común. Es tan curiosa como interesante su opinión crítica sobre el patrón oro. Pensaba Ruskin que el uso de metales preciosos como moneda, era una forma de trueque que reflejaba una profunda desconfianza en el Estado y en el gobierno; actitud que consideraba propia de las naciones bárbaras, pero no de los países civilizados. ${ }^{11}$ En resumen en esa nueva sociedad que recogiera lo mejor de Atenas y Esparta, el Estado dirigiría nuestras vidas como un gobernante ilustrado, en un mundo ordenado; algo que, en su opinión, los hombres de negocio de la época -acostumbrados a una sociedad desorganizada en la que unos tratan de pisotear a otroseran incapaces de entender. ${ }^{12}$

Son sólo dos ejemplos. Existe, ciertamente, una literatura bastante amplia en la época en la que se combinan la crítica al mercado y el pensamiento conservador. Me he limitado a hablar de Carlyle y Ruskin por el papel relevante que, en sus obras desempeña el culto al arte y a la tradición, que permite establecer vínculos interesantes entre su obra y la de los novelistas decadentes. En lo que a las ideas económicas hace referencia, pueden encontrarse semejanzas también con la obra de autores católicos y conservadores, críticos del liberalismo tanto en política como en economía, entre los que se puede mencionar como figuras destacadas a Villeneuve -Bargemont o a Le Play. Pero se trata de escritores que, aunque su conocimiento del análisis económico no fuera tampoco muy alto, realizaron estudios empíricos interesantes con una visión mucho más cercana a la realidad de la de Carlyle o Ruskin. Y sus obras están, desde luego, muy alejadas del profundo interés por el arte o los grandes hombres que mostraron aquéllos; y que tan presentes estuvieron también las novelas del decadentismo.

\section{Y EN EL PRINCIPIO FUE HUYSMANS}

La lectura de $A$ contrapelo suele resultar tan fascinante como sorprendente para quien recorre sus páginas por primera vez sin una idea previa de su contenido. La trama es muy simple. Se trata de una novela de un solo personaje, el joven duque Jean, último vástago de una vieja familia aristocrática, los Des Esseintes. Como la mayoría de los protagonistas de este tipo de novelas Jean es un hombre rico. Esta característica es fundamental, ya que, sin ella, su comportamiento y actitud ante la vida -elementos básicos de estas obras- resultaría, simplemente, imposible.

En su juventud Des Esseintes había conocido todo tipo de placeres mundanos; y había quedado hastiado. En un momento dado, se plantea cambiar totalmente su vida. Nada extraño hasta aquí. Pero nuestro protagonista resulta ser

\footnotetext{
${ }^{11}$ Ibid., pp. 175-176.

${ }^{12}$ Ibid., p. 145.
} 
también un completo neurótico; y decide que su futuro va a ser vivir en el aislamiento más completo separándose de una sociedad por la que siente un profundo desprecio. Para ello compra una mansión en Fontenay aux Roses, en las cercanías de París. La novela dedica muchas páginas a describir la decoración de esa casa y a sus gustos estéticos. Conocemos con detalle también sus lecturas y las ediciones de los libros de su biblioteca. Nos cuenta el autor cómo se organiza la vida en la mansión, los horarios y hasta la forma en la que tienen que moverse los criados para no hacer ruido. En algún momento el protagonista se plantea escapar de su jaula de oro y viajar por el mundo. Pero es demasiado esfuerzo; y, en cuestión de horas, vuelve a su casa. Sólo saldrá de ella cuando una enfermedad tan física como mental y el consejo de los médicos le obliguen a regresar a vivir a París, la ciudad que, para él, era el símbolo de la mediocridad humana. Y esta es toda la acción. Cabe preguntarse cómo una novela así pudo tener una influencia tan grande en la literatura europea. Y la respuesta es claramente que lo menos importante de ella es la trama, que sólo desempeña el papel de una débil estructura en la que descansa lo importante: las ideas y la estética del protagonista. ${ }^{13}$

Pero ¿cómo veía Des Esseintes la vida económica que soportaba este mundo de arte y alta cultura? El duque intentaba siempre rodearse de cosas bellas, como cuadros, libros y todo tipo de objetos exquisitos. Pero su reclusión tenía, ante todo, el objetivo de escapar de un mundo triste en el que la gente moría por conseguir dinero: "Al mismo tiempo que se generaba su deseo de escapar de una época odiosa, de indignas groserías, se había hecho por completo necesario para él para no volver a ver imágenes de seres humanos cumpliendo en París sus obligaciones entre cuatro paredes o moviéndose por las calles en busca del dinero". ${ }^{14}$

Cuando, forzado por los médicos tiene que volver a París, una de sus grandes preocupaciones es coexistir con la burguesía que había ascendido, poco a poco, en la escala social aprovechando todos los desastres para enriquecerse: "Terminada la aristocracia de cuna, existía ahora la aristocracia del dinero; era el califato de los mostradores, el despotismo de la calle de Santier ${ }^{15}$, la tiranía del comercio de ideas banales y estrechas, de instintos vanidosos y bribones. ${ }^{16}$

La burguesía era, en su opinión, más vil que la nobleza y el clero. Y se había vuelto contra el populacho, al que ella misma había incitado a enfrentarse a las

${ }^{13}$ Otras obras de este género podrían citarse en el mismo sentido. Por ejemplo, Monsieur de Phocas de Jean Lorrain carece también de acción real. Lorrain (2001).

${ }^{14}$ Huysmans (2003), p. 87.

${ }^{15}$ Calle de París conocida en aquella época por sus establecimientos de venta y confección de productos textiles.

${ }^{16}$ Huysmans (2003), pp. 294-295. 
viejas castas. Y lo que para él era, tal vez, lo más importante: el triunfo de la burguesía había significado la destrucción de la inteligencia y la muerte del arte. Era, en resumen, lo peor de América transportado a nuestro continente; idea que se confirma en el texto con numerosas referencias a la ordinariez de los financieros, al "tabernáculo impío de los bancos", etc., etc. ${ }^{17}$

Y lo más curioso de todas estas referencias es que no son meros recursos literarios con los que el novelista refuerza la imagen de su personaje. No. Huysmans creía realmente en lo que escribía. El novelista, en especial después de su conversión, pasó a mirar con nostalgia la sociedad medieval, un mundo basado en los principios de la religión, en el que el dinero desempeñaba un papel muy secundario. Como otros intelectuales de la época, defendió la vuelta a una producción basada en los gremios. La iglesia y las corporaciones serían, en su opinión, las únicas instituciones capaces de garantizar una economía basada en principios morales, algo que no podría hacer nunca el estado liberal-republicano, dominado por la burguesía y por los judíos. ${ }^{18}$ En los gremios padres e hijos trabajaban en el mismo oficio. La corporación les garantizaba el trabajo y el salario. Y no estaban sometidos al capital ni -lo que resulta interesante desde el punto de vista económico- tenían que sufrir las fluctuaciones del mercado. ${ }^{19}$ Un mundo, en resumen más justo, igualitario y seguro.

A diferencia de Wilde, Huysmans rechazaba el individualismo por considerarlo una fuerza destructiva de la sociedad. Pensaba que el individualismo generaba la existencia de negociantes que explotaban a sus trabajadores, vendían productos de mala calidad e, incluso, estafaban en el peso a sus clientes. Nadie escapaba a estos comportamientos; ni el rico financiero ni el modesto comerciante, ya que se trataba de un problema moral que a todos afectaba.

El dinero aparece en su obra literaria posterior a $A$ contrapelo relacionado con lo peor de la naturaleza humana y como un auténtico instrumento del diablo. No creo haber leído una crítica tan feroz al mundo de las finanzas y las actividades mercantiles como la que presentó Huysmans en el primer capítulo de su novela dedicada al satanismo, Allá abajo. Escribía allí que todo lo relacionado con el dinero era perverso. Pero nada más monstruoso que el dinero convertido en "capital": "Entonces su acción no se limita a incitaciones individuales, a consejos de robos y asesinatos, y se extiende a la humanidad entera. En una palabra, el capital decide los monopolios, construye los bancos, acapara las subsistencias, dispone de la vida y puede, si lo desea, ¡hacer morir de hambre a millones de seres!". ${ }^{20}$

\footnotetext{
${ }^{17}$ Ibid., p. 296.

${ }^{18}$ Seillan (2009), p. 310.

${ }^{19}$ Seillan (2009, p. 311.

${ }^{20}$ Huysmans (1985), pp. 39-40.
} 
Es interesante señalar que el año de la publicación de Allá abajo (1891) fue también el año de la encíclica Rerum Novarum de León XIII. Y que, como se ha apuntado en un apartado anterior, se había desarrollado en la Francia del siglo XIX un pensamiento económico católico, crítico del liberalismo tanto económico como político con el que Huysmans podía haber conectado. Pero es difícil encontrar alguna relación significativa entre estos movimientos y una obra literaria muy personal y fuertemente radicalizada. J. M. Seillan, el principal estudioso de las ideas religiosas y políticas de Huysman, ha insistido en esta idea y ha sacado a la luz una entrevista que, el año 1903, el escritor concedió a $L a$ Corporation, la revista de los círculos obreros católicos. Aunque se mostrada en ella conciliador con el catolicismo social, en realidad criticaba sus planteamientos y tachaba de blandos sus principios. Como el mundo que le tocó vivir no le gustaba, prefería mirar al pasado y no se preocupaba mucho de que sus críticas al liberalismo económico pudieran contribuir a reformar de manera razonable la economía y la sociedad del nuevo siglo. ${ }^{21}$

\subsection{Una nota sobre el naturalismo y la crítica al capitalismo}

A contrapelo se publicó en el momento cumbre del naturalismo en la novela, que alcanzó su máximo desarrollo con las veinte novelas del ciclo Les RougonMacquart. En 1884 Zola estaba empezando a redactar la decimotercera de la serie, Germinal. Y solo siete años después -en 1891- aparecería su gran novela sobre el mundo financiero, El Dinero; el mismo año en el que Huysmans publicó Allá abajo. Huysmans había sido, a lo largo de una serie de años, un defensor convencido de los principios del naturalismo y un miembro destacado del grupo de Médan, cuyo líder indiscutible era Zola. No era éste un hombre muy dispuesto a contemporizar en los debates en los que tomaba parte ni a aceptar ideas diferentes de las suyas en relación con la manera de escribir novelas. Por esta razón la reacción de Zola a la publicación de $A$ contrapelo fue mala. Parece que, al principio, vio el libro como una aventura literaria absurda y sin transcendencia, de la que su autor se arrepentiría pasado algún tiempo: "Este libro -escribía a Huysmans en 1890- será, al menos una curiosidad dentro de su obra". ${ }^{22}$ Pero la relación iría empeorando con el paso del tiempo, porque Huysmans no sólo estaba experimentando nuevos caminos literarios, sino que había pasado a rechazar por completo el naturalismo. En el primer párrafo del primer capítulo de Allá abajo, uno de los personajes, Des Hermies, afirma: "lo que reprocho al naturalismo no es la pintura gruesa de su estilo ordinario; es la inmundicia de sus ideas; lo que le reprocho es haber encarnado el materialismo en la literatura, ¡haber glorificado la democracia del arte!". ${ }^{23}$ La conversión de

\footnotetext{
${ }^{21}$ Seillan (2009), pp. 316-325.

${ }^{22}$ Baldick (1958), p. 115.

${ }^{23}$ Huysmans (1985), p. 27.
} 
Huysmans y su defensa de la Iglesia Católica lo alejarían totalmente de quien había sido su maestro. En el prólogo a la edición de A contrapelo de 1903 Huysmans relató la dura discusión que mantuvo con Zola en Médan al negarse éste a aceptar el nuevo camino emprendido por su antiguo discípulo. Ya no era un simple capricho literario a olvidar, sino que, en su opinión $A$ contrapelo había dado un "golpe terrible al naturalismo". ${ }^{24} \mathrm{Y}$ su postura frente a la nueva escuela era de total intolerancia: "no admito este cambio de maneras y de opinión -parece que le dijo Zola- no tolero que se queme aquello que se ha adorado". 25

Algunos pensadores liberales han considerado a Zola como un claro exponente de la mentalidad contraria al mercado presente en muchos escritores de la época. Mises, por ejemplo, en el capítulo que dedicó a "La literatura bajo el capitalismo" de su libro La mentalidad anticapitalista afirmaba que Zola consideraba que el capitalismo era el peor de los males y que sus novelas son una colección de homilías socialistas. ${ }^{26}$

Pero la obra del maestro del naturalismo es bastante más compleja. Y en algunos de sus escritos se encuentran opiniones mucho más matizadas. En un esbozo de El Dinero, Zola afirmaba que su objetivo era mostrar la vida en toda su fuerza; y señalaba que pretendía explicar cómo el dinero se había convertido en buena medida, en la base de la dignidad; cómo, en el mundo moderno, era el dinero el que hacía libres a los hombres y llevaba consigo la higiene, la limpieza, la salud y casi la inteligencia. Que tenía una fuerza irresistible y que era la palanca que movía el mundo. Reconocía el novelista que el dinero, ciertamente, enfrentaba a la clase acomodada y a la clase pobre. Pero -y esto es importante- decía con claridad que en su obra no intentaba enfrentar el que había venido a denominarse el "siglo del dinero" con los llamados "siglos del honor" del pasado. ${ }^{27}$ En otras palabras, no pretendía -como lo hacía claramente Huysmans- que el dinero fuera algo monstruoso y "el alimento más nutritivo de los pecados importantes". ${ }^{28}$

\section{GABRIELE D'ANNUNZIO, EL POETA SOLDADO}

Fue, sin duda, Gabriele D'Annunzio una figura de excepcional importancia no sólo en el mundo de la literatura, sino también en la vida política, social y cultural de Italia en el medio siglo que transcurrió desde la publicación de sus primeras obras en la década de 1880 hasta su fallecimiento en 1936, cuando

\footnotetext{
${ }^{24}$ Huysmans (2003), p. 19.

${ }^{25}$ Ibid., p. 20.

${ }^{26}$ Mises (1957), p. 25.

${ }^{27}$ Pagès y Morgan (2002), p. 295.

${ }^{28}$ Huysmans (1985), p. 39.
} 
estaba considerado como una auténtica gloria nacional y gozaba de una popularidad extraordinaria. Muchas veces se han puesto en relación las ideas políticas y económicas de D'Annunzio con el corporativismo fascista. Y bastante de cierto hay en ello. El momento cumbre de la vida política de nuestro escritor hay que situarlo en el año 1919. Héroe de la guerra, D'Annunzio invadió aquel año el territorio del Fiume -disputado entonces por Italia y el nuevo estado de Yugoslavia- al frente de varios cientos de legionarios, que no sólo lo aceptaban como líder, sino que, incluso, vestían los uniformes que él mismo les había diseñado. Allí proclamó la Regencia de Canaro; y su constitución refleja algunas ideas del anarco-sindicalismo que D'Annunzio había tomado de quien fue su colaborador en la aventura, Alceste de Ambris. La carta de Canaro influyó, ciertamente, en el corporativismo fascista. $\mathrm{Y}$ en ambos se pueden encontrar muchas de las ideas contrarias al liberalismo, a la democracia parlamentaria y a la economía de mercado que hemos visto florecer en las décadas finales del siglo XIX. Aceptado por el fascismo como el gran patriota y el alma cultural de la nueva Italia, parece que sus relaciones con Mussolini no fueron especialmente cordiales. Tal vez porque ambos fueron unos grandes actores que, en cualquier representación, solo podían aceptar el papel protagonista.

Pero la primera experiencia política de D'Annuncio había tenido lugar muchos años antes. En 1897, se había presentado a las elecciones al Parlamento por el distrito de Ortona a Mare, con el apoyo de las fuerzas conservadoras. Y ganó la elección; lo cual, sin embargo, no supuso un cambio importante en su vida. Desde el momento mismo de su incorporación a la Cámara sintió un gran desprecio por el parlamento, que puso de manifiesto en algunos de sus escritos; por ejemplo, en su novela Las vírgenes de las rocas, publicada sólo dos años antes de su aventura política. En ella presentaba una visión profundamente reaccionaria de la sociedad y se lamentaba del ascenso de las clases medias y de que el dinero y lo que denominaba "actividades útiles" hubieran sustituido a la tradición y a los principios de la vieja aristocracia como elemento fundamental para el gobierno del país. La visión que de la democracia parlamentaria refleja el libro es tan clara como demoledora, cuando su personaje, miembro de la antigua nobleza, se preguntaba si su clase debería "representar nuestro papel poniendo en la papeleta electoral los nombres de nuestros colonos, de nuestros sastres, de nuestros sombrereros, de nuestros zapateros, de nuestros usureros y de nuestros abogados". ${ }^{29} \mathrm{Y}$ al año siguiente de su elección comentaba a un amigo que tenía que viajar a Roma "para asistir a la miserable representación parlamentaria". ${ }^{30}$

No era, sin embargo, nuestro personaje un hombre que aceptara pasar desa-

\footnotetext{
${ }^{29}$ D'Annunzio (1995-B).

${ }^{30}$ Chiara (1978), pp. 109-116.
} 
percibido en ningún ambiente, ni siquiera en aquellos en lo que se sentía extraño, como era la vida política. Así el año 1900, el honorable D’Annunzio abandonó un día su escaño entre los diputados de la derecha, para sentarse con los de la izquierda. La razón formal era su oposición a una reforma del reglamento de la Cámara dirigida a frenar el obstruccionismo parlamentario, a la que los socialistas se oponían; pero lo que seguramente buscaba era un golpe de efecto, como tantas veces hizo a lo largo de su vida. Dado que D'Annunzio era un personaje muy conocido en Italia de la época, los diputados de la izquierda trataron de atraerlo en sus filas. El escritor no les hizo, sin embargo, el menor caso; y pocos días después de su actuación en la cámara se marchó a Viena a ver la representación de La Gioconda, que, en aquella ciudad, protagonizaba Eleonora Duse, la gran actriz dramática, que fue su amante durante cinco años.

Aunque buena parte de la obra de D'Annuzio presenta claras conexiones con el decadentismo, el libro que la sitúa en el centro de este movimiento en Italia y lo conecta directamente con Huysmans es El placer, su primera novela. El libro fue publicado en mayo de $1889 ; \mathrm{y}$, como había ocurrido con $A$ contrapelo en Francia, su aparición causó un gran escándalo en Italia. Desde el primer momento se puso en relación esta obra con la de Huysmans; y a su protagonista, el conde Andrea Sperelli-Fieschi con Des Esseintes. El mismo reconocía, aunque no con demasiado convencimiento, la existencia de puntos en común entre ambas obras; y así lo comentaba, por ejemplo, en una larga carta que escribió a su traductor francés, Georges Hèrelle el 14 de noviembre de 1892: "El placer es un libro muy curioso, impregnado de arte que guarda, tal vez, algún parentesco con A contrapelo de J.K. Huysmans". ${ }^{31}$

La novela se centra en las relaciones amorosas que Sperelli mantiene en Roma con dos mujeres casadas: Elena Muti, su antigua amante y María Ferres, esposa de un diplomático guatemalteco. Ambas relaciones terminan mal para el protagonista. Elena lo deja de lado, por su marido primero y por un nuevo amante más tarde. Y María decide, finalmente, permanecer fiel a su esposo cuando éste se arruina por el juego y debe abandonar Roma. El libro termina con un Sperelli solo en palacio Zuccari pensando, seguramente, en la definición que había dado de sí mismo en otro pasaje de la novela: un hombre camaleónico, quimérico, incoherente e inconsciente.

El conde era un esteta "impregnado por completo de arte". En palabras del novelista, era un resto de la vieja nobleza italiana, que de generación en generación había transmitido una tradición familiar de cultura selecta, elegancia y arte, en un mundo desagradable que es descrito como ese "diluvio democrático gris de nuestros días que ha sumergido, de forma miserable, muchas cosas hermosas

${ }^{31}$ D’Annunzio (1946), p. 130. 
y raras". ${ }^{32}$ Entre ellas estaban, sin duda, los libros antiguos y las ediciones y encuadernaciones exclusivas, que desempeñan un papel importante en las aficiones de los protagonistas de las novelas del decadentismo; libros que se imprimen ediciones de muy pocos ejemplares, lógicamente con costes altísimos. ${ }^{33}$

Frente a esta forma de entender la vida, la actividad de los comerciantes aparece en la novela como algo vil y despreciable. Y las personas que al comercio y a los negocios se dedican presentan una imagen similar. En la descripción de la subasta de los bienes del marido de María embargados por los acreedores se refleja perfectamente esta visión que enfrentaba al mundo selecto de los aristócratas, que compraban por afición y buen gusto, con el de los comerciantes, que lo hacían para revender. La subasta tiene lugar en verano, y buena parte de quienes forman la alta sociedad han abandonado Roma. Por ello "la mayor parte de los asistentes eran negociantes, revendedores de muebles usados, ropavejeros: gente baja". ${ }^{34} \mathrm{Y}$ si compraban no era ciertamente por la belleza de los objetos en venta, sino por la posibilidad de conseguir mercancías preciosas a precio vil. Estos personajes no despertaban precisamente la simpatía de Sperelli: "Un olor desagradable que emanaba de aquellos hombres impuros se transmitía por el aire caliente. Andrea se ahogaba" ${ }^{, 35}$ A Spirellli le daba asco que lo rozaran sus codos o su pies; la náusea le cerraba la garganta. Y cuando salió de la casa lo hizo con un sabor amargo y nauseabundo en la boca. El contacto con todos aquellos desconocidos lo había dejado como infectado de oscuras enfermedades para las que no había medicina: "La tortura física y la angustia moral se mezclaban". Pero el problema no era sólo suyo. Su vida se había hundido, como lo había hecho también el mundo en el que él intentaba vivir.

\section{OSCAR WILDE: EL ESTETICISMO EN LA FÁBRICA DEL MUNDO}

El desarrollo de un arte y una literatura esteticista es un fenómeno curioso en la Gran Bretaña del siglo XIX. Inglaterra, la nación del comercio y las finanzas, la fábrica del mundo, fue también cuna de escritores, pintores, escultores y arquitectos cuyo universo se encontraba muy lejos de las factorías de Manchester y de los bancos de la City de Londres. Wilde fue uno de ellos. Y, aun así, la economía del país más próspero de Europa está presente en su obra. Como en buena parte de la literatura del siglo pasado, sus personajes hablan continuamente de dotes, herencias e inversiones en deuda pública al tres por ciento. En alguna de sus comedias, como en Un marido ideal, el dinero y la ambición son

\footnotetext{
${ }^{32}$ D’Annunzio (1995-A), p. 31.

${ }^{33}$ Ibid., pp. 151 y 240.

${ }^{34}$ Ibid., p. 266.

${ }^{35}$ Ibid., p. 266.
} 
los auténticos protagonistas de la obra. Pero, seguramente, el texto más conocido de Wilde, en relación con la economía, es un delicioso fragmento del segundo acto de La importancia de llamarse Ernesto. En el escenario aparece el jardín de una residencia solariega en Woolton. Es el mes de julio y hace ese calor tan habitual en las comedias inglesas y tan raro en la vida real. La institutriz, Miss Prism, está en clase con su pupila, la señorita Cecilia Cardew. Pero debe ausentarse antes de terminar su lección y da a su discípula las siguientes instrucciones: "Cecilia, hará usted el favor de estudiar su lección de economía política durante mi ausencia. El capítulo sobre la baja de la rupia puede usted saltárselo. Es demasiado sensacional. Hasta esos problemas monetarios tienen su lado melodramático". ${ }^{36}$

El efecto que Wilde buscaba está muy bien conseguido. No cabe duda de que la cotización de la rupia -tema importante para las finanzas inglesas de la época, al que, por cierto, Keynes dedicó su primer libro- debió parecer a un hombre como Wilde algo curioso, y hasta pintoresco. En la escena lo admirable es la forma de mencionar la cuestión, la expresión elegante e irónica, como la de quien hace un comentario insustancial al pasar por delante de un escaparate extraño o de un cuadro absurdo colgado en una galería de arte.

Resulta interesante comparar esta actitud ante los problemas económicos con la que hemos visto en un apartado anterior de personajes mucho más serios y transcendentes como Carlyle o Ruskin. Los tres coincidían en muchas cosas, en especial en su rechazo al espíritu mercantil. Como a Carlyle o a Ruskin, a Wilde no le gustaba vivir en una sociedad que ponía como meta el éxito económico, aunque fuera precisamente esa sociedad la que durante años lo trató con admiración y le permitió vivir como un hombre acomodado. Así, en su conferencia sobre "El renacimiento inglés del arte", afirmó de forma contundente que no puede existir una gran escultura, ni un gran teatro, en un país que no tenga una noble vida nacional; para añadir, a continuación, que el espíritu mercantil de Inglaterra había matado esa vida noble; y, por tanto, la posibilidad de crear arte". ${ }^{37}$ Pero nuestro escritor era demasiado frívolo y vitalista para deprimirse por una cosa así. Parece que no podía tomar en serio ni siquiera aquello que más le importaba. Y tampoco era, desde luego, capaz de condenar abiertamente en su obra literaria lo que menos le gustaba. Cada vez que en sus comedias hay una referencia a un tema económico, sus críticas fluyen ligeras, e incitan más a la sonrisa que al rechazo.

En este sentido Wilde estaba muy lejos de Huysmans. Pero no cabe duda de que su obra más conocida, y la más relevante para un estudio del decadentismo,

\footnotetext{
${ }^{36}$ Wilde (1963), p. 340.

37 The English Renaissance of Art, texto no incluido en la edición de obras utilizada. Vid. www.online-literature.com/wilde/2013.
} 
El retrato de Dorian Gray, es difícil de entender sin la influencia de $A$ contrapelo. El capítulo 11 de la novela de Wilde empieza con las siguientes palabras: "Durante años Dorian Gray no pudo librarse de la influencia de este libro. O, tal vez, sería más exacto decir que nunca intentó librarse de ella". ${ }^{38}$ Nos cuenta Wilde que su personaje encargó a París no menos de nueve ejemplares de la obra que mandó encuadernar en colores diferentes que pudieran ser adecuados para sus cambiantes estados de ánimo. Ni el título del libro ni su autor son mencionados; pero la referencia a la novela de Huysmans es tan evidente que nadie la ha puesto nunca en duda. Wilde buscó este acercamiento y dejó claro en su libro que Dorian Gray se veía retratado en el joven parisino; y que la vida de aquél mostraba, de alguna forma, su propia trayectoria vital antes de que él mismo la hubiera experimentado. ${ }^{39}$

El retrato de Dorian Gray se publicó por primera vez en las páginas del Lippincott's Monthly Magazine en junio de 1890. Y en los meses siguientes Wilde amplió la obra, que pasó de los trece capítulos originales a 20, y ofreció al lector la nueva versión como libro en abril de 1891. La historia es tan conocida que no merece la pena narrarla aquí en detalle. El hombre joven, apuesto, amante del arte, que, de una forma especial, vende su alma para conservar la eterna juventud mientras su retrato, escondido en un desván de la casa envejece; y que, con el tiempo, se convierte en un disoluto que no duda en llegar al asesinato de uno de sus mejores amigos, Basil Hallward, el autor del retrato que da título a la obra. El tercer personaje importante es Lord Henry Wotton, que es, en buena medida, quien pervierte al joven Gray. Hombre cínico y corrupto, critico de los valores victorianos, tanto en lo que se refiere a los principios morales básicos como a los fundamentos económicos de la sociedad en la que vive. Como le ocurría a D'Annunzio y en, menor grado, a Wilde en la vida real, el consumo de bienes de lujo era uno de los objetivos de su vida y no importaba demasiado que cobrara quien se los había sumistrado. ${ }^{40}$ Cuando Lord Henry visita a su tío Lord Fermor, el viejo aristócrata está convencido de que viene a pedirle dinero; pero Henry lo niega: "No quiero dinero -dice- el dinero lo quieren quienes pagan sus cuentas... y yo nunca pago las mías". ${ }^{41}$

El consumo suntuario está presente a lo largo de todo el libro. También hay aquí cuadros, esculturas, libros, muebles y telas preciosas. Y la novela insiste

\footnotetext{
${ }^{38}$ Wilde (1963), p. 102.

${ }^{39}$ Ibid., p. 102.

${ }^{40}$ En el caso de D’Annunzio esta obsesión por el lujo llegó a tal extremo que, en 1910, tuvo que refugiarse en Francia para escapar de sus acreedores. Y pasaron cuatro años antes de que consiguiera regresar a Italia, lo que pudo hacer gracias al apoyo que le prestaron los grupos de presión que buscaban la entrada de Italia en la guerra contra Austria y Alemania, conflicto en el que, en su opinión, su país debería participar.

${ }^{41}$ Wilde (1963), p. 38.
} 
una y otra vez en las diferencias radicales que separaban la vida de las clases altas de la existencia de los trabajadores. El teatro modesto en el que actuaba Sibyl Vane -de quien en algún momento de la novela Dorian Gray estuvo enamorado y que más tarde se suicidó cuando éste la abandonó- es descrito por Wilde de forma no muy diferente a cómo Huysmans presentaba la visión que de París tenía Des Esseintes, o a cómo D’Annunzio narraba la subasta que producía angustia y repulsión a Sperelli. En la novela, Gray, Basil y lord Henry van a la sala a ver actuar a Sybil Vane. Los recibe el empresario, y Wilde nos detalla que éste es un "judío gordo", con manos enjoyadas, que se comporta con una humildad pomposa. Hace mucho calor. Los hombres que forman aquel público tan poco distinguido se han quitado las chaquetas y pelan naranjas, que ofrecen a las chicas que los acompañan, a las que Wilde describe como vulgares y sin gusto. Algunas mujeres ríen a gritos y sus voces son horriblemente agudas y disonantes. Ante este ambiente, tan desagradable y opresivo, Lord Henry hace un comentario cruel para Dorian y su enamorada: "¡Vaya un sitio para encontrar a una divinidad!". ${ }^{42}$

Son dos sociedades que se encuentran a mucha distancia una de otra, aunque las clases altas y bajas vivan en la misma ciudad. Wilde estaba, sin duda, muy lejos del mundo de los trabajadores. Pero no era servil hacia los ricos. Por el contrario, su ironía era terriblemente destructiva para ellos. Las viejas duquesas o los aristócratas inútiles de la época victoriana que aparecen en sus obras son, a menudo, personajes ridículos. Y también lo son los políticos y los empresarios. De un diputado radical en el Parlamento, que acudía a las cenas de Lady Agatha, sabemos que, en su vida pública, seguía a su líder político; pero, en su vida privada, seguía a los mejores cocineros y prefería cenar con los conservadores. ${ }^{43} \mathrm{Y}$ ¿qué decir de los hombres de negocios? Pocas frases tan demoledoras para el mundo de las finanzas pueden encontrarse en la literatura de cualquier época como aquel sencillo comentario de Lord Henry sobre los efectos que produce en la sociedad el ir bien vestido: "Con un frac y una corbata blanca, cualquiera, aunque sea un agente de bolsa, puede llegar a ser considerado un hombre civilizado". ${ }^{44}$

\subsection{Un peculiar ensayo sobre el socialismo}

Oscar Wilde ofrece una visión muy particular del socialismo en su ensayo "El alma del hombre en el socialismo". Su defensa de esta doctrina se basa en la curiosa idea de que sólo en un sistema tal podría llegar a su plenitud el individualismo y triunfar un nuevo helenismo, que constituía su ideal de vida. La tesis

\footnotetext{
${ }^{42}$ Ibid., p. 71.

${ }^{43}$ Ibid., p. 42.

${ }^{44}$ Ibid., p. 21
} 
de este ensayo resulta bastante sorprendente. El socialismo, en opinión de Wilde, no haría que cada hombre mostrara mayor preocupación e interés por los demás seres humanos. Todo lo contrario. En sus propias palabras, "el socialismo nos libraría de la sórdida necesidad de vivir para los demás". Nada veía tan lamentable como el altruismo o la necesidad de combatir la pobreza. La imagen que transmitía de los pobres no era especialmente halagüeña. Los pobres eran tipos que, en su opinión, no tenía educación, ni cultura, ni encanto en su forma de hablar, ni refinamiento alguno. Habría que evitar que existieran, por tanto. Esto se lograría con el socialismo y así las mentes más cultivadas podrían ser libres realmente y desentenderse de los demás, como hacían Keats, Flaubert o Byron, que consideraba ejemplos destacados de grandes hombres y grandes individualistas de su siglo. ${ }^{45}$

Pensaba Wilde, en contra de una muy antigua tradición del pensamiento social y económico, que la propiedad privada "aplasta" el individualismo y constituye una auténtica desgracia para la humanidad porque, además de permitir conseguir placeres implica también obligaciones que él consideraba "insoportables". El individualismo lograría, además, gracias al socialismo, la abolición de la familia en la forma hasta entonces conocida y abriría un nuevo camino a las relaciones entre los hombres y las mujeres. ${ }^{46}$

A diferencia de otros críticos de la economía de mercado, que creían en las virtudes del trabajo, y en concreto del trabajo manual, Wilde lo despreciaba absolutamente: "Muchas tonterías se han dicho y escrito acerca de la dignidad del trabajo manual; pero no hay nada que dignifique el trabajo manual y, en la mayoría de los casos éste es absolutamente degradante". ${ }^{47}$ Por ello confiaba en la maquinaria como un instrumento que liberaría al hombre del trabajo manual. $\mathrm{Si}$, en su opinión, toda cultura se basa en el ocio, y no en la actividad productiva; si toda civilización requiere esclavos que permitan a algunas personas dedicarse a la creación artística e intelectual, la esperanza para la humanidad radica en hacer que los esclavos sean las máquinas y el hombre pueda así dedicar su vida a otras actividades.

Su visión elitista se refuerza aún más cuando el arte -el gran tema del decadentismo- es analizado desde el punto de vista de la sociedad. "El arte -escribía Wilde- es la manifestación más intensa del individualismo que el mundo ha conocido". ${ }^{48}$ Naturalmente sólo una clase social puede conocerlo y disfrutarlo. En El retrato de Dorian Gray, Lord Henry hace explícita esta visión de la profunda separación de valores en la sociedad de la época: "El crimen es algo ex-

\footnotetext{
${ }^{45}$ Ibid., p. 1.018.

${ }^{46}$ Ibid., p. 1.025 .

${ }^{47}$ Ibid., p. 1.027 .

${ }^{48}$ Ibid., p. 1.029.
} 
clusivo de las clases bajas... Diría que, para ellos, el delito desempeña la función que el arte tiene entre nosotros; simplemente un método de conseguir sensaciones extraordinarias". ${ }^{49} \mathrm{Y}$ ni siquiera todos los miembros de las clases acomodadas lo entienden. Pensaba Wilde que, si el arte depende del público, va hacia su perdición. En sus propias palabras, "En Inglaterra las artes que mejor han escapado (de la decadencia) son aquellas que no interesan al público. La poesía es un ejemplo de lo que quiero decir". ${ }^{50}$

Como en buena parte de la literatura de la época, en la obra de Wilde hay frecuentes referencias al Renacimiento italiano, considerado como un momento histórico en el que los artistas desempeñaron un papel muy importante en la sociedad, ese papel que a los autores del decadentismo les gustaría que recuperaran sustituyendo a los sórdidos industriales y comerciantes. Pero nuestro autor añadía una idea interesante, en la línea de la tesis principal de su ensayo. "El Renacimiento -escribía- fue grande porque no intentó resolver problemas sociales ni se ocupó de tales cosas, sino que permitió a los individuos un desarrollo libre, hermoso y natural; y por ello surgieron grandes artistas únicos y grandes hombres únicos". 51

Como los otros escritores cuyas ideas hemos analizado, Wilde no sentía especial aprecio por la democracia: "En algún momento se crearon grandes esperanzas con respecto a la democracia; pero la democracia significa simplemente, el apaleamiento del pueblo por el pueblo para el pueblo. ${ }^{52}$ Para él existen tres clases de déspotas: el príncipe, el papa y el pueblo. Todos ellos suponen un peligro y una amenaza para el arte. Pero los príncipes pueden ser personas cultivadas; y muchos lo han sido. Los papas pueden ser personas cultivadas; y muchos lo han sido. Pero "la autoridad del pueblo es ciega, sorda, horrorosa, grotesca, trágica, divertida, seria y obscena. Todos los déspotas sobornan; pero el pueblo soborna y embrutece". Y su conclusión es clara: "para un artista resulta imposible vivir con el pueblo". ${ }^{3}$

Estas ideas recuerdan, de alguna forma a la conocida frase sobre el despotismo del Marqués de Sade, uno de los autores que más fascinaban a los escritores del decadentismo. Sade, que había sido encarcelado en los años de la monarquía absoluta, lo fue también en los tiempos de la Revolución, en los que estuvo condenado a muerte y parece que salvó la vida por un simple error burocrático. En un momento de tristeza no dudó en afirmar que, tras haber conocido el tiranía de la monarquía absoluta, estaba convencido de que nada podía com-

\footnotetext{
${ }^{49}$ Ibid., p. 160.

${ }^{50}$ Ibid., p. 1.030 .

${ }^{51}$ Ibid., p. 1.039

${ }^{52}$ Ibid, p. 1.026.

${ }^{53}$ Ibid, p. 1.038 .
} 
parase con la tiranía de la Revolución. Pero el hombre necesita vivir; y necesita hacerlo de forma plena y perfecta, sin que otros pongan límites a lo que quiere hacer. El individualismo era, para Wilde, la única esperanza para la creación y la vida libre. Pero, curiosamente sólo el socialismo le permitiría vivir así, sin esa absurda y desagradable actitud de ayudar a nuestro prójimo necesitado.

\section{UNA REFLEXIÓN FINAL: EL DECADENTISMO Y EL MUNDO REAL}

¿Existieron realmente personajes como los protagonistas de estas novelas? ¿Hubo alguna vez hombres como Des Esseintes, Sperelli o Gray? La figura con la que más a menudo se les ha comparado es la del conde de MontesquiouFézensac, aquel curioso aristócrata exquisito, poeta y ensayista, homosexual, amigo de artistas, que vivió entre 1855 y 1920. En 1891 Edmond de Goncourt escribía en su diario la siguiente entrada: "Visita a Montesquiou-Fézensac, el Des Esseintes de A contrapelo". ${ }^{54}$

Pero no cabe duda de que los tres autores estudiados compartían mucho de la visión del mundo y las ideas de sus protagonistas. Wilde carecía, ciertamente, de los instintos criminales de Dorian Gray. Pero la obsesión por la estética y el arte, que constituyen una parte esencial de la novela, eran tan suyas como de su protagonista. Y su desprecio por la actividad económica no era sólo literario, sino vital. D'Annunzio fue él mismo un esteta. Y su vida real fue mucho más novelesca que la de cualquiera de sus personajes. Las náuseas de Andrea Sperelli al encontrarse junto a comerciantes y a "gente baja" pudo haberlas sentido también el escritor. Más complejo es el caso de Huysmans, cuya trayectoria vital y humana experimentó muchos cambios a lo largo del tiempo; y se ha dicho que Des Esseintes está muy lejos tanto del escritor naturalista inicial como del católico ferviente de la segunda parte de su vida. Pero algunos biógrafos han negado esta separación radical entre autor y personaje y mantenido que el novelista utilizó a Des Esseintes para expresar sus propias ideas. Baldick, por ejemplo, defiende esta tesis y afirma que "el auténtico modelo de Des Esseintes es, como ha señalado Leon Bloy, el propio Huysmans. ${ }^{55}$

El decadentismo como fenómeno literario duró poco. No cabe duda de que, en Inglaterra, el segundo proceso de Oscar Wilde, que llevó a su condena y encarcelamiento, contribuyeron a desprestigiar no sólo su obra literaria sino también todo el movimiento esteticista en Gran Bretaña ${ }^{56}$ Pero también en Francia

${ }^{54}$ Citado por H. Zinck en su estudio sobre la novela Monsieur de Phocas, incluido en Lorrain (2001), p. 137.

${ }^{55}$ Baldick (1958), p. 107.

${ }^{56}$ Es interesante señalar que la prensa de la época estableció de forma muy clara esta relación. El National Observer, por ejemplo, tras felicitarse por la condena del escritor, al que tachaba de 
y en Italia la novela seguiría pronto otros caminos. Y al cabo de algunos años tanto Huysmans como D’Annunzio buscarían nuevas vías.

Muchas de las ideas sociales y políticas que, a finales del siglo XIX inspiraron el mundo del decadentismo y otros movimientos intelectuales seguirían vivas, sin embargo; y el rechazo al liberalismo y a la economía de mercado se extendieron por todo el mundo en las primeras décadas del siglo siguiente. Tanto en la derecha como en la izquierda cobró fuerza creciente la idea de que era posible prescindir de los hombres de negocios y de las empresas privadas, en una nueva economía dirigida por el Estado. Las consecuencias fueron, sin duda, desastrosas para Europa.

\section{REFERENCIAS BIBLIOGRÁFICAS}

BALDICK, R. (1958). La vie de J. K. Huysmans. Paris: Ed. Denöel.

CHIARA, P. (1978). Vita de Gabriele D’Annunzio. Milano: Mondadori.

D'ANNUNZIO, G. (1946). Correspondance à Georges Hérelle. Paris : Ed. Denöel.

D'ANNUNZIO, G. (1995). Il piacere. Roma: Newton.

D'ANNUNZIO, G. (1995). Le vergini delle rocce. Roma: Newton.

HENDERSON, W. (1999). John Ruskin's Political Economy. Routledge.

HUYSMANS, J.K. (1985). Là-Bas. Paris : Gallimard.

HUYSMANS, J-K (2003). À rebours. Paris : France Loisirs.

KAPLAN, M. B. (2004). "Literature on the Dock: The Trials of Oscar Wilde". En Journal of Law and Society 31,1. pp. 113-130.

LORRAIN, J. (2001). Monsieur de Phocas. Ed. De H. Zinck. Paris : Flammarion.

MARX, K. y ENGELS, F. (1965). Le Manifeste Communiste. En K. Marx, CEuvres I.

Économie. Paris: Gallimard, pp. 157-195.

MISES. L. (1957). La mentalidad anticapitalista. Valencia: Fundación I. Villalonga.

PÁGES, A y MORGAN, O. (2002). Guide Emile Zola. Paris: Ellipses.

ROSE, H. (1891). New Political Economy. The Social Teching of Thomas Carlyle, John

Ruskin and Henrry George. BiblioLife.

RUSKIN (1907). The political Economy of Art. London: Routledge.

SEILLAN, J.M. (2009). Huysmans: politique et religion. Paris: Editions Classiques

Garnier.

WILDE,O. (1963). Works. London: Collins.

ZOLA, E. (1980). L'Argent. Paris: Gallimard.

"obsceno impostor", señalaba que debería celebrarse otro juicio en el que se condenara a los decadentes y su abominable concepción del arte. Citado por Kaplan (2004), p. 129. 